\title{
Historicidade e olhares sobre o processo saúde-doença: uma nova percepção
}

\author{
Everaldo de Santana Silva \\ Doutorando PPGMA \\ Universidade do Estado do Rio de Janeiro (UERJ) \\ $\triangle$ everaldo.desantana@gmail.com \\ Gustavo Aveiro Lins \\ Doutorando PPGMA \\ Universidade do Estado do Rio de Janeiro (UERJ) \\ 凹gu.lins@terra.com.br \\ Elza Maria Neffa Vieira de Castro \\ Prof ${ }^{\mathrm{a}}$ Doutora PPGMA \\ Universidade do Estado do Rio de Janeiro (UERJ) \\ 凹elzaneffa@gmail.com
}

Recebido em 27 de junho de 2016

Aceito em 17 de outubro de 2016

\section{Resumo:}

No evoluir da história das sociedades, os maiores flagelos associados à vigilância em saúde decorreram de fatores intrínsecos à construção das comunidades, o que evidencia a íntima relação da saúde com as condições ambientais. O olhar da biomedicina sobre a saúde humana prioriza soluções corretivas em detrimento das preventivas, pois privilegia o pensamento cartesiano, com a tradicional diagnose e profilaxia, condicionado pela mercantilização do conhecimento científico. Com o objetivo de fomentar uma reflexão crítica sobre o processo saúde-doença, este estudo defende a necessidade de mudança de paradigma na biomedicina, propugnando a quebra da hegemonia e do monopólio da medicina científica, com vistas a atenuar preconceitos e a permitir a adoção de diferentes terapêuticas para os enfermos.

Palavras-chave: Meio ambiente e saúde pública; Paradigma integrativo; Promoção da saúde; Saúde holística.

\section{Historicity and perspectives on the health-disease process: a new insight}

\begin{abstract}
:
During the course of the societies' history, the greatest scourges linked to health surveillance resulted from intrinsic factors to the construction of communities, which shows an intimate relationship between health and environmental conditions. The look of biomedicine on human health focus on corrective solutions over preventive ones, because it follows the Cartesian thought with the traditional diagnosis and prophylaxis, conditioned by the commercialization of scientific knowledge. With the purpose of fostering a critical reflection about the health-disease process, this study defends the need of a paradigm shift concerning biomedicine, defending a break on the hegemony and monopoly of the traditional medicine to mitigate prejudices and allow different therapeutic to the sick.

Keywords: Environment and public health; Integrative paradigm; Health promotion; Holistic health.
\end{abstract}




\section{Historicidad y perspectivas sobre la salud enfermedad: una nueva percepción}

\section{Resumen:}

Durante el curso de la historia de las sociedades, las mayores plagas relacionadas con la vigilancia de la salud se debieron a factores intrínsecos a la construcción de comunidades, que muestra una relación íntima de la salud con las condiciones ambientales. El aspecto de la biomedicina en la salud humana prioriza soluciones correctivas en detrimento de las preventivas, pues privilegia el pensamiento cartesiano con tradicional diagnosis y profilaxis, condicionadas por mercantilización del conocimiento científico. Con el objetivo de fomentar una reflexión crítica sobre el proceso de la salud enfermedad, este estudio defiende la necesidad de cambio de paradigma en la biomedicina, propugnando la ruptura de la hegemonía y del monopolio de la medicina científica, con el objetivo de atenuar prejuicios y a permitir la donación de distintas terapéuticas terapéuticas para los enfermos.

Palabras clave: Medio ambiente y salud pública; Paradigma integrativo; Promoción de la salud; Salud holística.

\section{INTRODUÇÃO}

Este artigo analisa o paradigma da medicina cientificista instaurado no Brasil no século XX, que exerceu influência, tanto na formação do profissional de saúde quanto nas relações da prática médica. Para tanto, apresenta a conjugação do modelo flexneriano de medicina com as estratégias de reprodução sociometabólica do capital que se traduzem no caráter de neutralidade da formação técnico-científica, na qualificação do profissional de saúde adequado às exigências do modo de produção capitalista e na abordagem do indivíduo como ser biológico, compartimentado e isolado da natureza sócio-político-ambiental na produção da sua existência física, emocional, mental e espiritual.

Embora o modelo flexneriano tenha consolidado o método científico na questão médica, fortalecido as especialidades e ampliado os avanços tecnológicos nas esferas diagnósticas e terapêuticas (tomografia computadorizada, ressonância nuclear magnética, laparoscopia, litotripsia, endoscopia), com redução de custos financeiros, seu contínuo desenvolvimento vem demandando questionamentos e reflexões sobre a adequação deste modelo às diretrizes curriculares dos cursos de medicina e às necessidades da atual conjuntura brasileira (CASTRO, 2004).

Nessa perspectiva, este artigo explicita alguns elementos históricos da relação ambiente natural e ambiente social na sociedade ocidental; os pressupostos fundamentadores das questões sanitárias e econômicas em suas articulações com as ideologias, processos de produção e de consumo do sistema capitalista, com vistas a contribuir para a reflexão sobre a formação integrativa capaz de redirecionar a prática 
médica visando à obtenção de um estado global de saúde, a recuperação integral do paciente e a prevenção das doenças, a partir das novas necessidades sociais relativas ao cuidado médico.

\section{CAMINHOS HISTÓRICOS DA RELAÇÃO SAÚDE-AMBIENTE NO MUNDO OCIDENTAL}

Na história das sociedades, os maiores flagelos associados à vigilância em saúde decorreram de fatores intrínsecos à construção das comunidades, o que evidencia sua íntima relação com as condições ambientais (ROSEN, 2000). Essa visão relacional entre saúde e ambiente originou-se na Grécia com Hipócrates, cujas ideias contribuíram para a formulação de conceitos como endemia e epidemia, ainda que de forma rudimentar, a partir do entendimento que a enfermidade era produto da interferência do meio ambiente e, em especial, das mudanças atmosféricas na saúde dos seres humanos.

Essa perspectiva fortaleceu-se com a conquista da Grécia pelos romanos, quando o conhecimento grego foi incorporado ao saber do povo dominador, pois os preceitos filosóficos e de engenharia gregos já eram aplicados às comunidades, com medidas de saneamento básico, como distribuição de água, esgotamento de resíduos sólidos e banhos públicos. Após o declínio do império romano, a causalidade das doenças tomou outro viés com a manifestação da patologia atribuída à realidade supra-sensível e a cura relacionada à fé, o que provocou a eliminação de hábitos e de processos higiênicos, como o banho e o fornecimento de água corrente para a limpeza das moradias, culminando em um período marcado por grandes epidemias (GUTIERREZ, 2001). A cultura clássica grega, portanto, é importante na evolução do conceito de saúde em sua busca por uma explicação racional dos processos de doença que, mais tarde, se expandiu para a busca do equilíbrio corpo/mente, a partir de análises das causas biológicas e sociais, considerando a observação empírica, o ambiente, o trabalho e o contexto social (GUTIERREZ, 2001).

No período de colonização do novo mundo, especulações apontam que a dizimação da população americana ocorreu, em grande parte, por doenças trazidas pelos colonizadores que, por sua vez, também foram vitimados por moléstias tropicais. Dados deste período apontam a ocorrência de morte de $95 \%$ da população pré-colombiana, em virtude de surtos epidêmicos de doenças como a gripe e o sarampo (ALMEIDA FILHO, 2009). 
Nos séculos XVI e XVII, a teoria miasmática, formulada por Thomas Sydenham e Giovanni Maria Lancisi, postulava que as doenças resultavam de miasmas (contaminação no grego antigo) - odores fétidos provenientes de matéria orgânica em putrefação nos solos e nos lençóis freáticos contaminados e transportados pelos ventos. Apoiada neste pressuposto, a teoria contagionista admitia a transmissão de enfermidades por contato físico, cujo material infeccioso associado a microrganismos (LEWINSOHN, 2003) contaminava o ar, a água, as roupas ou pertences do enfermo. As políticas preventivas da primeira relacionavam-se à limpeza de edifícios públicos e pântanos. A segunda defendia uma ação radical de isolamento e reclusão do enfermo.

No século XIX, a teoria microbiana tornou obsoleta a teoria miasmática e o velho mundo presenciou o surgimento e a propagação de diversas doenças infecto-contagiosas devido, em parte, ao aumento populacional e às péssimas condições de vida das sociedades industriais. A instauração dessas doenças nas sociedades europeias provocou investimentos para o seu enfrentamento, tais como os aplicados na Reforma Sanitária da Inglaterra, que resgatou a teoria hipocrática sobre o ambiente e a saúde (SILVA, 2012).

Com a confirmação da teoria microbiológica e com o consequente desenvolvimento de ações imunológicas e profiláticas, grande avanço científico ocorreu na luta contra as infecções, ocasionando brusca queda no número de casos em todo mundo, o que gerou mudança do paradigma de ações preventivas (no meio ambiente) para corretivas (medicamentos e vacinação). Entretanto, em meados do século XX, um processo de resistência abalou a concepção microbiana e fomentou reflexões e discussões preventivas no tocante à conservação ambiental como condição sine qua non para a mitigação de doenças, com as questões de saneamento caracterizando os determinantes ambientais em saúde (HELLER, 1998).

No início do século XX, o médico norte americano Abraham Flexner elaborou um estudo que lançou as bases para a consolidação da medicina cientificista, cujo desenvolvimento tecnológico baseava-se em terapêuticas assistenciais e em possibilidades hospitalocêntricas, inclusive com valorização da aprendizagem e com prevalência da formação especialista disciplinar sobre a formação generalista interdisciplinar, da ótica individual sobre o ser integral e coletivo e das práticas curativas sobre as preventivas. 0 tratamento do corpo humano como máquina, com suas "peças" cuidadas separadamente, 
negando ao paciente o status de sujeito, vai ao encontro dos pressupostos anunciados no Relatório Flexner.

Os novos desafios colocados pela revolução quântica neste século (Planck, Einstein, Bohr, Heisenberg, Prigogine, dentre outros) contribuíram para ampliar o questionamento dos cientistas, levando-os a reverem o paradigma clássico e a construir um novo movimento científico que propusesse a reforma do pensamento, com base em pressupostos que religam os conhecimentos sobre a matéria, a vida, o ser humano e a sociedade (MORIN, 1998). Nessa perspectiva, a visão de mundo que insere o ser humano na natureza demonstrou a importância de se perceber a relação do meio ambiente com o surgimento e a distribuição de patologias. Embora essa percepção tenha alicerçado a construção da Geografia Médica e da Medicina Social e fornecido subsídios à Epidemiologia, esta conexão ainda apresenta obstáculos subjetivos e práticos na sociedade contemporânea. O entendimento deste relacionamento extrapola os fatores naturais de causalidade e amplia-se para os condicionantes sociais incorporando as intervenções das atividades antrópicas.

\section{ALÉM DA VISÃO REDUCIONISTA}

Oriundo do conceito de phisis e da noção de totalidade, provenientes da filosofia présocrática (FOCAULT, 1997), o conceito de saúde encontra sua gênese na íntima relação entre medicina e filosofia. Mas, influenciado por características próprias de cada período histórico, esse conceito sofreu alterações ao longo dos tempos. Desde os primórdios da humanidade, o ser humano questiona-se sobre a origem da vida, as razões da existência e o que é ter saúde. Do mesmo modo, parece-nos que todo profissional de saúde deveria colocar-se diante desse questionamento essencial e existencial: o que é a saúde? como o meu trabalho pode se tornar um meio de promovê-la?.

Da associação da clínica com o laboratório no século XX até hoje, a medicina científica alicerçou-se em pressupostos mecanicistas, descritivos e analíticos fundados em noções de causalidade e linearidade, pressupondo a razão e o todo como somatório das partes, sustentáculos da reprodução do sistema capitalista e dos ideais positivistas (CAMARGO, 1993). Esta lógica legitima a competência dada à ciência de ser a única forma de descrever a realidade e, ao médico, de prescrever a "pílula mágica" que exterminará o mal instalado no corpo e na mente dos seres humanos. Para essa visão reducionista, a doença 
ocorre através de uma linha objetiva de fatos concretos, obtidos por meio de dados sistemáticos de estudos científicos (TESSER, 2002). Com um plano de ação traçado, universal, igualitário e eficaz pressupõe-se que ... de cada doente só se teria que resolver o enigma de descobrir qual a entidade doença que nele se apresenta e eliminá-la (TESSER, 1999) Para o pensamento científico, as doenças têm causas, consequências e tratamentos determinados, demandando metodologias que iluminam o caminho a ser seguido para eliminá-la. Nesse universo de certezas, cabe exclusivamente ao médico identificar e aplicar o sistema que legitima a ciência como receptáculo da verdade e os médicos como seus arautos - diagnosticadores e prescritores de drogas, concebidas pela própria ciência.

Tal processo faz do médico um ignorante especializado e do cidadão um ignorante generalizado (SANTOS, 2001). Desta forma, este preceito metodológico se fortalece, moldando a realidade ao processo de cura, restringindo e dirigindo o olhar dos saberes e das ações instituídas a seu respeito, garantindo a certeza no conhecimento científico, sem questionamentos de essência epistemológica, ontológica ou até mesmo lógica (PHILLIPI, 2011).

A medicina moderna tem como primazia o caráter corretivo dos flagelos, o que distanciou, por muito tempo, o diálogo entre setores de saúde e setores ambientais (CASANOVA, 2006), ocasionando ações pontuais, fragmentadas, que estimulam esse olhar distanciado do objeto. Exemplo disso são as doenças ditas negligenciadas que não só prevalecem nas condições de pobreza mas, também, contribuem para a manutenção da desigualdade socioambiental, tendo em vista que são consideradas indicadoras dessas condições e promotoras de entraves para o desenvolvimento dos países (BRASIL, 2002).

Não se pode ingenuamente pensar sobre estes fatos sem visualizar que tanto a ciência como os médicos são utilizados como mecanismos de controle e de reprodução sociometabólica do capital, com a ciência exercendo a função de autoregulação. 0 processo saúde/doença é um fenômeno eminentemente social e mutável, cujas manifestações dependem direta ou indiretamente da estrutura social de reprodução das condições materiais que se efetiva por meio do trabalho transformador da natureza. Pensar a saúde ou a doença como um fenômeno que se revela na sociedade, como um processo social, demanda compreender o contexto social em que as doenças ocorrem, pensá-las para além de suas causas biológicas, entendê-las na perspectiva de que as pessoas ou os corpos estão interligados com as outras pessoas de seu grupo de trabalho, de sua família, de sua 
comunidade, de sua classe social. Assim, da oposição ser humano/natureza surge e se organiza uma série de relações mediadoras - sociais e biológicas - capazes de problematizar a concretude dos processos de saúde/doença dos seres humanos.

Ao criar "nichos" de construção de conhecimentos isolados, pragmáticos e homogêneos, com vistas a legitimar o saber científico como único capaz de interpretar a realidade, o capital alia-se à ciência para instaurar o que pode ser considerado como "tirania de massa" (LATOUR, 2001). A força motivadora desse processo depende da importância e da intensidade dos interesses dos grupos sociais e pode ser estimulada pela necessidade, pelo desejo ou por impulsos oriundos e direcionados por objetivos específicos (ARRUDA, 2010). Assim, o sistema dominante acaba por imputar sua lógica e rede de influências como modelo tecnológico de alta eficiência, eficácia e qualidade, manipulando e iludindo seus súditos fiéis: ...quando componentes estúpidos simples se articulam de maneira apropriada, desempenham papéis inteligentes que tomam corpo e se expressam de forma cognitiva e ativa (CASANOVA, 2006).

A mercantilização da ciência consiste em fazer com que ela funcione como mercadoria dentro da lógica do capital, ou seja, na perspectiva de que todo produto tem valor de troca. Entender essa questão demanda análise acurada do modo de produção capitalista mas, tal análise torna-se mais complexa quando o objeto é o conhecimento intelectual: nesse caso específico, a ciência.

A lógica da privatização do conhecimento legitima-se pela capacidade de venda daquilo que o conhecimento pode gerar em termos de lucro e de poder. Assim, tanto a informação quanto a desinformação têm a função de constituir-se em poder e em mercadoria. Para isto, a ciência deve ser quantificada, interagindo com as práticas neoliberais que irão executar a funcionalidade de imposição do caráter de mercadoria a todo conhecimento científico (OLIVEIRA, 2008).

Se a realidade é preconizada pela ciência, e esta é aceita pela massa que, por sua vez, é controlada e regida pela lógica dominante, o véu que obscurece o processo de construção da realidade configura-se encobrindo o árduo, polêmico, tortuoso (e espinhoso) caminho da construção do conhecimento autônomo, até que pareça pura evidência (LATOUR, 1997). No campo do cuidado à saúde, este pensamento acaba por tecnificar e desumanizar a conexão médico-paciente, redefinindo a relação para uma perspectiva de fornecedor-cliente, 
capitalista-consumidor. Assim, a funcionalidade da medicina tem essência curativa objetiva, com práticas corretivas ditadas e orientadas pela hegemonia capitalista, mediante metodologias, agentes e curas direcionadas, que se desenrolam em uma relação distanciada entre o observador e o observado, cujo poder - seja lá qual for sua intenção - aumenta à medida que são produzidos resultados previstos pela lógica determinista e alienante.

$\mathrm{Na}$ visão biomédica, toda enfermidade tem suas determinações e tratamento conhecidos, e qualquer forma de cura, agravações, sintomas ou sinais que sejam inexplicáveis por esta lógica cartesiana são fenômenos indignos de interesses científicos e negados, reinterpretados ou omitidos pelos médicos. A sociedade fica ansiosa pelo brilhantismo dos médicos no tocante à cura que, por sua vez, foram isentados da responsabilidade e do poder da terapêutica, ora entregue a indústria farmacêutica, ora às pesquisas científicas. Contrariando esta matriz de pensamento, Phillipi Jr. e Silva Neto (2011) afirmam que o ser humano possui formas de enxergar e de interpretar a si próprio e ao mundo em que vive, o que permite adquirir um conhecimento da totalidade da realidade. Essas possibilidades de entender o mundo se opõem à visão reducionista da ordem aparente, que fragmenta o mundo e o simplifica em um mundo físico e biológico.

Os desafios contemporâneos ocasionados pelas crises socioambientais globais já não conseguem ser explicados e nem mesmo solucionados pelo antigo paradigma, que não dá mais conta das complexas problemáticas da contemporaneidade. A realidade representada pela interação do ser vivo com o mundo onde vive apresenta várias condicionantes que podem magnificar ou mitigar um evento, dependendo de sua análise espaço-temporal.

Atualmente, não se pode mais buscar produzir conhecimento dividindo a realidade em partes para entender o todo a partir de elocubrações descontextualizadas nem, tampouco, eliminar uma enfermidade com medicamentos e tratamentos pontuais, sem traçar uma rede ampla de conhecimentos capaz de indicar a causa do agravo e estabelecer as relações que possam indicar o caminho da cura efetiva.

Corroborando esta ideia, Camargo Jr.(1993) afirma que não existe uma única teoria ou um único conceito biomédico de doença capaz de explicar toda a rede de causalidades e de interações existentes no mundo atual. Para o autor, encontrar respostas pressupõe um processo dinâmico, complexo, interacional, que abrange a pesquisa e a prática de profissionais de saúde em relação a este mundo, considerando que o contexto não é 
moldado por verdades apriorísticas, mas se constitui de uma transformação permanente, de evidências relacionais, subjetivas e provisórias - um mundo dentro de outros mundos.

O tratamento médico na sociedade tem caráter disciplinar, determinado pelos "olhos singulares" da ciência médica que leva em conta o conhecimento gerado e adquirido no campo da biomedicina sem interseção com outras áreas do conhecimento e com isolamento do paciente do meio circundante. Aliado a esta fragilidade metodológica na produção e na significação do conhecimento encontra-se a formação dos profissionais de saúde fundamentada no modelo flexneriano. O processo de transição deste modelo para um modelo integrativo com foco não só no problema mas, no indivíduo e na saúde coletiva, desponta no horizonte formativo brasileiro expressando a incorporação da categoria da totalidade (BARATA, 2006). Após a Constituição de 1988, o direito à saúde passou a ser considerado como um dos pontos centrais de atenção do Estado, o que culminou na criação do Sistema Único de Saúde (SUS), cujo resgate das intervenções preventivas gerou a necessidade de se formar profissionais médicos capacitados e comprometidos em empreender esforços e ações institucionais que possibilitem alcançar níveis elevados de qualidade no processo produtivo e na formação de recursos humano (CASTRO, 2004).

Segundo Casanova (2006), as novas ciências, identificadas como sistemas complexos auto regulados e com as novas concepções do caos, vêm buscando o reconhecimento, o diálogo e a combinação entre as variáveis na modelação de cenários para tomadas de decisão, de modo a construir ações em que as relações são definidas pelos sujeitos envolvidos que, por sua vez, são definidos por estas relações, num processo dialético de auto-modelagem, que ocorre mutua e ciclicamente. Este novo pensamento, que perpassa também a atual medicina humanizada, se constitui de diferentes olhares, diagnósticos, formas de interação e de cura, o que facilita o diálogo entre paciente e médico e contribui para a superação da condição de separação sujeito observador/objeto observado.

A inclusão crítica das tecnociências e dos sistemas complexos autoregulados pode contribuir na formação dos profissionais, não exclusivamente da área da saúde, para que exerçam suas escolhas na busca das melhores opções para alcançar a saúde plena das populações. Importa salientar que essas escolhas comportam elementos racionais e emocionais, práticos e éticos, científicos e estéticos, que correspondem à criação humana, entre contradições, de um mundo novo, de um sistema social global que ai nda não existe. 
Nessa perspectiva, ocorrem várias possibilidades de resposta para o mesmo problema médico e essas distintas soluções perpassam níveis diferentes de interpretação da realidade. $\mathrm{Na}$ dimensão individual, a cura pode ser alcançada pela administração de medicação (alopática, homeopática, fitoterápica), de dieta (incluindo jejum), de prescrição de banhos, acupuntura, massagem, fisioterapia e outros tratamentos. Na dimensão social, muitos problemas podem ser tratados e prevenidos pela nutrição correta, pela higienização dos corpos e dos ambientes, pela disponibilidade de água potável, pela vacinação, pela ausência de contato com fontes de poluição e outros agentes patogênicos etc. Entretanto, ainda que diferentes em dimensão e ação, todos esses elementos se configuram como ação terapêutica no processo de cura, no âmbito da busca pelo bem estar e por melhor qualidade de vida.

$\mathrm{Na}$ atualidade, insuficientes espaços têm sido abertos para esta discussão no âmbito das ciências médicas, tendo em vista que a biomedicina e os processos alternativos à lógica alopática configuram-se como excludentes. Contudo, é exatamente neste flanco que a interdisciplinaridade se apresenta como uma nova possibilidade. Em uma análise mais complexa, percebe-se que as contradições se vinculam, interagem e se complementam definindo-se e redefinindo-se constantemente, em uma relação dialética de separação e união.

Assim, as tensões herdadas de séculos de embates entre ciência e processos tradicionais de cura, por exemplo, podem estimular atuações em co-relação e, com isto, a necessidade de posse da verdade pode dar lugar à abertura de novos horizontes para a realização de uma medicina mais atualizada com as demandas socioambientais.

\section{UM PORTO DE VÁRIAS VIAS}

A dificuldade no entendimento da relação meio ambiente e saúde pode ser analisada quando nos propomos a entender os efeitos das mudanças climáticas sobre a saúde. Esta análise é complexa e requer uma abordagem interdisciplinar dos profissionais de saúde, epidemiologistas, climatologistas, biólogos, físicos, químicos, cientistas sociais, dentre outros, na visualização das relações interdependentes dos sistemas sociais, econômicos, biológicos, ecológicos e físicos com as alterações do meio ambiente que envolve inúmeras variáveis interligadas atuando mutuamente para a construção de um determinado cenário. 
A ocorrência de uma patologia é determinada pela exposição ao seu agente etiológico em associação a fatores históricos, sociais, econômicos, identificados através de inquéritos epidemiológicos e de metodologias participativas em gestão ambiental.

Diante deste problema, é fundamental repensar a formação médica, tendo em vista que o modelo biomédico instituído é limitado por uma estrutura conceitual que não permite aos profissionais lidarem com a interação corpo/mente/meio ambiente. A ciência médica reduz-se a estudar alguns aspectos fisiológicos, não relacionando os aspectos biológicos da doença com as condições físicas e psicológicas gerais do organismo humano e com o seu meio ambiente. Na epidemiologia, mais do que ausência de saúde, o que ocorre é a visão da doença como falha no mecanismo regulador de equilíbrio entre o meio interno (organismo doente) e o meio externo (fatores ambientais) (AYRES, 1992).

A história natural de uma patologia divide-se em um período pré-patogênese, conhecido como o momento das relações entre os fatores endógenos e os exógenos, preparando o cenário para o período patogênico, no qual ocorrem as primeiras interações, ocasionando o processo de sintomatologia específico (ALMEIDA FILHO, 2003). O ambiente torna-se fator preponderante na magnificação ou mitigação de uma doença, apresentando determinantes que interagem com os fatores específicos do agente causador e o hospedeiro no processo de promoção ou da manutenção da patologia.

Dessa forma, a melhoria dos níveis de saúde depende muito mais de ações sobre estilos de vida e meio ambiente e de novos conhecimentos sobre biologia humana, do que de expansão da rede de hospitais e de outros serviços de saúde.

Esta perspectiva permite vislumbrar que o indivíduo infectado será o hospedeiro se sua função for servir de substrato onde a infecção evolua e exteriorize a doença. E será tomado como fator ambiental ao participar como reservatório do bioagente (ROUQUAYROL, 1999). Ainda sobre este prisma, os bioagentes podem ser transmitidos por agentes abióticos contaminados que servem de transporte (veículos), introduzindo assim o agente etiológico no ambiente.

A expectativa do controle, e até mesmo da solução das doenças infecto-contagiosas pela ação de vacinas e de antibióticos não se sustentou por muito tempo, apesar do declínio vertiginoso das taxas de incidência e de prevalência (GRISSOTI, 2010). As doenças infecciosas são causadas por bioagentes patogênicos que, quando possuem mecanismos de transmissão, são renomeadas como doenças infecciosas transmissíveis. Porém, muitos 
microrganismos possuem complexas estratégias e estruturas de adaptação e de mutação, o que acaba por conferir aos mesmos algum tipo de imunidade.

O Center for Diseases Control (CDC) define doenças emergentes como aquelas patologias infecciosas cuja incidência aumentou nas duas últimas décadas ou tendem a aumentar no futuro. Entretanto, esta definição é vaga, uma vez que diferentes circunstâncias podem caracterizar a emergência de novos problemas de saúde, pois nem sempre é possível saber se tais infecções são realmente inéditas ou se já se presentificaram.

A debilitação das economias tem relação com as causas das doenças transmissíveis, principalmente as tropicais, pois as alterações climáticas e as atividades antrópicas impactam, direta ou indiretamente, o meio ambiente (BARATA, 2006). Essas enfermidades vêm emergindo de forma cada vez mais dinâmica e acelerada, ocasionadas, principalmente, pelo tráfico microbiano que, na maioria dos casos, caracteriza-se pela transmissão de vetores dos animais para os humanos (MORSE, 1995). O conhecimento dos processos de transmissão das doenças é a base estrutural de qualquer estudo epidemiológico, em que a biologia do agente causador, possíveis reservatórios, dinâmica do ecossistema e condições ambientais são tópicos essenciais na formulação do estudo. Entre os fatores determinantes das infecções, podemos destacar as mudanças ambientais causadas por atividades antrópicas, tais como: mudança ecológica, anomalias no clima, densidade e comportamento humano, agricultura, processos migratórios (encorajados por fatores econômicos ou guerras) transporte, indústria, comércio, tecnologia, subsídios para resistência microbiana, entre outros (CONFALONIERI, 2002).

\section{A VISÃO DA ARANHA}

As novas potencialidades etiológicas têm provavelmente sua origem em fenômenos de interatividade com determinantes antrópicos que geram processos mutacionais ou de resistência em bioagentes já existentes, assim como o aumento do campo de atuação dos mesmos. O processo de degradação ambiental vem contribuindo para esta dinâmica, aumentando os habitats de vetores e expondo cada vez mais as populações humanas a vários riscos à saúde. Isto gera novos padrões epidemiológicos que requerem novos estudos e conhecimentos. 
As problemáticas em torno da saúde pública, e dentre elas estão inseridas as doenças infecciosas, constituem indicadores de um processo crítico-construtor de mudanças globais. A determinação de critérios de qualidade ambiental passa pela mensuração da relação causa-efeito nas atividades econômicas. Grande parte da alocação de recursos e do fomento a ações mitigadoras dependerá da fração da população atingida. Esta relação elucida o antagonismo de fragmentos populacionais coexistindo em um mesmo espaço geográfico (seja ele mundial, continental, nacional, regional ou local) e, com isto, amplia-se a discussão sobre os conceitos de vulnerabilidade, desigualdade social e justiça ambiental. Segundo Barata (CONFALONIERI, 2002), com a institucionalização da linha de pobreza, o monitoramento da relação da saúde com as condições de vida das sociedades revelou tendências e padrões de saúde entre pobres e não pobres, e comparações entre vários países ou até mesmo dentro do contexto nacional.

A problemática do saneamento encontra-se fortemente associada ao modelo econômico, onde a parcela da população mais vulnerável é excluída dos benefícios do desenvolvimento. Na América Latina, e especificadamente no Brasil, há grande lacuna entre políticas públicas de saneamento e políticas de saúde, congruindo para ações que acabam por desvalorizar as práticas de saúde, inclusive a formação de profissionais (PORTO, 2005). A inacessibilidade a recursos, ocasionada pela posição de um grupo abaixo da linha de pobreza, determina a instalação de desigualdades absolutas, enquanto desigualdades dentro de um mesmo grupo social ocasionaram as desigualdades relativas que, em saúde, podem ser descritas por duas vertentes:

(i) as que se referem ao perfil patológico da população, fortemente relacionada pela organização social e pela inserção do indivíduo na mesma e; (ii) as que se referem à oferta de serviços, que são mais fortemente influenciadas pela política nacional de saúde, as quais poderão ser reduzidas ou eliminadas por meio de sistemas universais (BARATA, 2006).

A proximidade entre saúde e ambiente traça duas linhas complementares: no olhar da saúde, o ambiente é valorizado como fator determinante de agravos à saúde e, sob a ótica do ambiente, vislumbram-se as suas alterações como agente ativo deste circuito. 


\section{ANÁLISE DE RISCO}

O processo de avaliação de risco constitui-se como uma importante ferramenta no processo de gestão ambiental, como subsídio técnico aos processos decisórios para a implementação de ações de remediação e de prevenção de danos ao sistema ambiental e à sociedade exposta a agentes perigosos, danos estes gerados a partir de produtos, processos produtivos e pela disposição de resíduos perigosos. A questão implica na articulação entre conhecimento e ação, relação esta que se apresenta como uma grande lacuna, principalmente nos países da América Latina. O desconhecimento e a desinformação contribuem para a ineficiência das medidas de prevenção e de controle (PERIALGO, 2007).

Tradicionalmente, as ações específicas do setor de saúde relativas aos riscos ambientais concentram-se nos efeitos adversos ocasionados à saúde humana, por meio de ações assistenciais e de recuperação, bem como de sistematização e de análise dessas informações (LUIZ, 2006). Isto é feito, por exemplo, mediante estudos epidemiológicos sobre a distribuição de certas doenças na população ou ainda por meio de estudos analíticos em que ocorre a relação entre a exposição a um determinado fator de risco e o efeito adverso causado à saúde. Porém, tais efeitos são apenas consequências finais para a saúde humana de um longo processo em que vários determinantes e condicionantes gerais, decorrentes do desenvolvimento econômico e tecnológico, atuaram ou poderão atuar sobre certos territórios e grupos populacionais (HACON, 2005).

Portanto, para que se possa agir efetivamente na promoção da saúde ambiental na perspectiva da saúde coletiva faz-se necessária a compreensão integrada, sistêmica e espacial dos riscos ambientais de uma determinada região. Em um espaço delimitado, esses riscos podem ser minimizados por meio de mobilizações solidárias com grupos diretamente envolvidos nas ações locais de gerenciamento e controle que os eliminam ou reduzem a níveis aceitáveis, assim como as suas consequências. O desenvolvimento desse processo deve ser transparente para permitir a participação dos atores sociais nas etapas do processo, desde a formulação do problema até a implementação de medidas alternativas de redução, mitigação ou eliminação dos riscos, seu monitoramento e contínua avaliação das ações gerenciais. 


\section{CONSIDERAÇÕES FINAIS}

Em uma análise histórica da evolução das doenças, observa-se o papel do meio ambiente nas proposições médico-científicas como agente determinante de inúmeras causas de doenças existentes no Brasil e na América Latina. No contexto atual, posta a complexidade das interações que o ser humano realiza com si mesmo e com o meio ambiente, em um mundo cada vez mais dinâmico e degradado, percebe-se a necessidade de a medicina avançar na superação da lógica racionalista cartesiana e no modelo flexneriano, dado que seus fundamentos não respondem mais às demandas do processo saúde-doença, instaurado para as populações que vivem situações de vulnerabilidade e de riscos.

O desafio de tratar a saúde do indivíduo e não a doença, decorrente de uma nova forma de interpretar a realidade, deve ser respondido trocando-se o paradigma determinista por outro reversível e desordenado, no qual processos e atores evoluam e se auto definam mutuamente em um movimento cíclico autoregulador. Nesta ótica, busca-se instaurar uma nova ciência que não aceite o reducionismo imposto pelo modelo capitalista ou que supere a visão hospitalocêntrica com prescrição de medicamentos que desconsidera o viés de prevenção pautado em uma investigação integral do sujeito e de possibilidades de tratamentos preventivos e alternativos, com a criação de vínculos mais afetivos do médico com o paciente, que passa a ser ativo em seu processo de equilíbrio e cura.

\section{REFERÊNCIAS}

ALMEIDA FILHO N.. Uma breve história da epidemiologia. cap.1. In: Rouquayrol MZ, Filho NA. Epidemiologia \& saúde. 6ª ed. Rio de Janeiro: Editora Guanabara Koogan; 2003.

ALMEIDA FILHO, N..; MEDRONHO, R.A.. Formação histórica da epidemiologia In: Medronho, R. A., Block, K. V., Luiz, R. R., Werneck, GL. Epidemiologia. São Paulo: Editora Atheneu; 2009.

ARRUDA, L.; QUELHAS, Q. L. G.. Sustentabilidade: um longo processo histórico de reavaliação crítica da relação existente entre sociedade e o meio ambiente. Boletim Técnico SENAC: A R. Educ. Prof. 2010 set/dez 36(3): 53-63, 2010.

AYRES, J.R.C.M.. O problema do conhecimento verdadeiro na epidemiologia. Revista de Saúde Pública.; 26 (3): 206214. 1992.

BARATA, R.C.B.. Desigualdades sociais e saúde. Tratado de saúde coletiva. São Paulo: Hucitec; 2006. p. 457-86. parte 3.

BRASIL. Ministério da Saúde, Departamento de Ciência e Tecnologia, Secretaria de Ciência, Tecnologia e Insumos Estratégicos. Doenças negligenciadas: estratégias do Ministério da Saúde. Revista de Saúde Pública. 2002; 44(1):2002.

CAMARGO, J.R.. Racionalidades médicas: a medicina ocidental contemporânea. Rio de Janeiro: Instituto Médico Social da Universidade do Estado do Rio de Janeiro; 1993. (Série Estudos em Saúde Coletiva 65). 
CASANOVA, P.G.. As novas ciências e as humanidades: da academia à política. Rio de Janeiro: Boitempo Editorial; 2006.

CASTRO, F.N.V.. Estratégias integrativas para formação e prática médica no Brasil: um estudo nas faculdades privadas do Estado do Rio de Janeiro. [Dissertação de mestrado]. Rio de Janeiro: Universidade Federal do Rio de Janeiro; 2004.

CONFALONIERI U.E.C.; CHAME M, NAJAR A.; CHAVES S.A.M.; KRUG T.; NOBRE C.. Mudanças globais e desenvolvimento: importância para a saúde. IEUS.; 11(3): 139-54. 2002.

FOCAULT, M.. O nascimento da clínica. Rio de Janeiro: Editora Forense Universitária; 1997.

GRISSOTI, M.. Doenças infecciosas emergentes e a emergência das doenças: uma revisão conceitual e novas questões. Ciência e Saúde Coletiva. 15 (supl.1): 1095-104. 2010.

GUTIERREZ, P.R.; OBERDIEK, H.I.. Concepções sobre a saúde e a doença. In: Andrade, SM.; Soares, DA; Cordoni, JL. (organizadores). Bases da saúde coletiva. Londrina: UEL; 2001.

HACON, S.; BARROCAS P.; SICILIANO S.. Avaliação de risco à saúde humana: uma contribuição para a gestão integrada de saúde e ambiente. Cadernos de Saúde Coletiva. 2005;13 (4): 811-36. 2005.

HELLER, L.. Relação entre saúde e saneamento na perspectiva do desenvolvimento. Ciência e Saúde Coletiva. 1998; 3(2):73-84.

LATOUR, B.. A esperança de Pandora: ensaios sobre a realidade dos escudos científicos. São Paulo: Editora Edusc; 2001.

LATOUR, B; WOLLGAR, S. A vida de laboratório: a produção dos fatos científicos. Rio de Janeiro: Relume Dumará, 1997.

LEWINSOHN, R.. Três epidemias: lições do passado. São Paulo: Editora Unicamp; 2003.

LUIZ O.C.; CONH A.. Sociedade de risco e risco epidemiológico. Cadernos de Saúde Pública. nov; 22(11):2339-48. 2006

MORIN, E.. Ciência com consciência. Rio de Janeiro, Bertrand Brasil; 1998.

MORSE, S.S.. Factors in the emergence of infectious diseases. Perspectives Emerging Infectious Diseases. 1995.1(1): $7: 14$.

OLIVEIRA, M.B.. A avaliação neoliberal na universidade e a responsabilidade social dos pesquisadores. Scientle Studia. 2008; 6(3): 379-87.

PERIALGO, M.; GALVÃO, L.A.; CORVOLAN, C.. Saúde ambiental na América Latina e Caribe: numa encruzilhada. Saúde e Sociedade. $2007 ; 16(3): 14-9$.

PHILLIPI JR. A.; SILVA NETO, A J.. Interdisciplinaridade em ciência, tecnologia e inovação. São Paulo: Editora Manole; 2011.

PORTO, M.F.S. Estratégias para um gerenciamento de riscos ambientais contextualizado, justo e participativo. Cadernos de Saúde Coletiva. 2005; 13 (1): 113-30.

ROSEN, G.. Uma história da saúde pública. São Paulo. Editora Unesp; 2000.

ROUQUAYROL M.Z.; GOLDBAUM M.. Epidemiologia, história natural e prevenção de doenças. cap. 2. In: Rouquayrol MZ, Filho NA. Op. cit. 1999.

SANTOS, B.S.. Um discurso sobre as ciências. Porto: Edições Afrontamento; 2001.

SILVA, E.S.. Possibilidade de emergência de cólera no porto do Rio de Janeiro. [Dissertação de mestrado]. Rio de Janeiro: Universidade Federal Fluminense; 2012.

TESSER, C.D.. A biomedicina e a crise da atenção à saúde: um ensaio sobre a desmedicalização. Dissertação de Mestrado. Campinas: Departamento de Medicina Preventiva e Social da Universidade Estadual de Campinas, 1999.

TESSER, C.D.; Luz, M.T.. Uma introdução às contribuições da epistemologia contemporânea para a medicina. Ciência \& Saúde Coletiva. 2002; 7(2): 363-72. 